\title{
Screening for gastric cancer in Japan
}

\author{
Yoshitaka Tsubono ${ }^{1,2}$ and Shigeru Hisamichi ${ }^{1}$ \\ ${ }^{1}$ Division of Epidemiology, Department of Public Health and Forensic Medicine, Tohoku University Graduate School of Medicine, \\ 2-1 Seiryomachi, Sendai 980-8575, Japan \\ ${ }^{2}$ Department of Nutrition, Harvard School of Public Health, Boston, MA, USA
}

\begin{abstract}
In Japan, mass screening for gastric cancer with photofluorography was initiated in 1960. At present, over 6 million people are screened annually. The sensitivity and specificity of photofluorography are $70 \%-90 \%$ and $80 \%-90 \%$, respectively. The 5-year survival rate is $15 \%-30 \%$ better in screendetected cancers than in symptom-diagnosed cases. Although no randomized controlled trials have been reported, cohort and case-control studies generally showed a decreased risk of mortality from gastric cancer in the screened subjects. The summary odds ratio ( $95 \%$ confidence interval) of three casecontrol studies for ever screened versus never screened subjects was $0.39(0.29-0.52)$ for men and $0.50(0.34-0.72)$ for women. Substantial evidence indicates that the Japanese screening program with photofluorography is effective in reducing the mortality from gastric cancer. The measurement of serum pepsinogens has recently drawn attention as an alternative to photofluorography, given its lower cost and simplicity. Some studies have suggested a comparable accuracy for the two methods. However, these investigations may have overestimated the relative sensitivity of serum pepsinogen testing compared with photofluorography, because serum pepsinogen testing was conducted as prevalent screening, while photofluorography was done as incident screening. Furthermore, no studies have directly examined whether the screening with serum pepsinogens reduced gastric cancer mortality. Therefore, at present, evidence is insufficient to determine the benefit of this program.
\end{abstract}

Key words Gastric cancer $\cdot$ Screening

\section{Introduction}

Mortality from gastric cancer in Japan is among the highest in the world [1]. The death rate has continued to decline during the past several decades, but gastric

Offprint requests to: $\mathrm{S}$. Hisamichi

Received: April 10, 2000 / Accepted: May 30, 2000 cancer still remains one of the major causes of cancer death among Japanese men and women [2].

With the hope of controlling premature deaths from gastric cancer, roentgenographic screening of the asymptomatic population was initiated in 1960 in Miyagi, Japan [3-7]. With the establishment of the Japanese Society of Gastric Mass Survey in 1962 (later renamed "Gastroenterological" Mass Survey), the program has spread throughout the nation. The implementation of the National Health and Medical Services Law for the Aged in 1983 was a landmark legislation for the expansion of the screening, because it mandated the national government to provide financial subsidies to municipal governments to offer annual screening for residents aged 40 years and over. In 1996, 6.4 million people were screened, $53 \%$ at community centers and $47 \%$ at their workplaces; $12.4 \%$ of the participants were referred for further examinations, and 6903 cases of gastric cancer were detected [8]. The subsidy by the national government was halted in 1998 .

This article summarizes the Japanese studies of screening for gastric cancer with photofluorography (indirect roentgenography), and briefly reviews the studies on new screening program with the measurement of serum pepsinogens.

\section{Accuracy of screening photofluorography}

The most common screening test is gastric photofluorography with an image intensifier, which is often provided in a specially designed mobile unit. According to the standardized procedure proposed by the Japanese Society of Gastroenterological Mass Survey, seven consecutive photofluorograms, covering the whole area of the stomach, are taken for each screenee, using roll films that are 70 or $100 \mathrm{~mm}$ in width [9]. Trained radiographic technicians take the photofluorogram, using effervescent granules without hypotonic 
agents. Two radiologists examine the films. A screenee with a suspected abnormality is referred for further diagnostic examinations that include full-size radiography, endoscopy, and biopsy.

The accuracy of a screening test is indicated by its sensitivity and specificity $[10,11]$. Sensitivity is defined as the proportion of persons screened positive among those with a detectable preclinical phase (DPCP) of the target disease, and specificity as the proportion of persons screened negative among those without DPCP. A good screening test must have both high sensitivity and high specificity. The identification of false-negative cases is a critical part of quantifying these indices. The most common method used in photofluorographic studies is to follow-up persons screened negative and to ascertain the cancer cases occurring among them through a record linkage to a population-based cancer registry and other data sources.

Table 1 summarizes the sensitivity and specificity of gastric photofluorography assessed by 1-year follow-up studies [12-21]. Two definitions of false-negative have been used. The first definition refers to cases identified within 1 year of follow-up. The second definition includes cases identified within 1 year of follow-up, plus cases detected by the screening conducted in the subsequent year. The sensitivity among studies ranged from $66.1 \%$ to $90.1 \%$, the specificity from $77.2 \%$ to $92.0 \%$, and the positive predictive value from $0.8 \%$ to $2.0 \%$. The studies generally showed an acceptable accuracy. Murakami et al. [20] reported that photofluorography with an image intensifier and direct radi- ography had comparable sensitivity $(88.5 \%$ and $90.8 \%$, respectively) and specificity $(92.0 \%$ and $91.4 \%$, respectively).

\section{Benefit of early detection}

A number of studies have reported that screen-detected gastric cancers showed an earlier stage distribution [2230 ] and had a lower case fatality rate than symptomdiagnosed cases [22,23,25,30-33]. The proportion of early gastric cancer among screen-detected cases is $15 \%-30 \%$ higher than among symptom-diagnosed cases (Table 2). The 5-year survival rate is also $15 \%-$ $30 \%$ better in screen-detected cases than in symptomdiagnosed cases.

Better prognosis of screen-detected cancers should be regarded only as a tentative indicator of the potential benefit of screening, because it is subject to lead-time bias and length bias [10,11]. Lead-time bias occurs in a way that the survival of screen-detected cases appeared to be lengthened, whereas the screening simply advances the time of the diagnosis and extends the period between diagnosis and death, without actual prolongation of life. Length bias refers to the tendency of screening to detect slow-growing lesions with better prognosis and to miss fast-growing lesions with poorer survival, which results in a lower case fatality for screendetected cases even if the screening, by itself, does not improve the prognosis. The efficacy of the screening should therefore be evaluated in terms of whether the

Table 1. Accuracy of screening photofluorography assessed by 1-year follow-up studies of general population

\begin{tabular}{lcclll}
\hline Author & $\begin{array}{c}\text { No. of } \\
\text { subjects }\end{array}$ & $\begin{array}{c}\text { Definition of false- } \\
\text { negative }^{\mathrm{f}}\end{array}$ & Sensitivity (\%) & Specificity (\%) & $\begin{array}{c}\text { Positive predictive } \\
\text { value }(\%)\end{array}$ \\
\hline Hisamichi [12] & 1185359 & 2 & $90.1(1775 / 1970)$ & $82.9(981301 / 1183389)$ & $0.9(1775 / 203863)$ \\
Sugahara [13] & $132163^{\mathrm{a}}$ & 2 & $71.8(260 / 362)$ & $87.6(115419 / 131801)$ & $1.6(260 / 16642)$ \\
& $178115^{\mathrm{b}}$ & 2 & $70.4(310 / 440)$ & $90.1(160064 / 177675)$ & $1.7(310 / 17921)$ \\
Iwai [14] & 4025 & 2 & $84.2(16 / 19)$ & $77.2(3092 / 4006)$ & $1.7(16 / 930)$ \\
Hosokawa [15] & 36786 & 2 & $71.8(79 / 110)$ & $81.3(29809 / 36676)$ & $1.1(70 / 6946)$ \\
Fukao [16] & 155938 & 2 & $69.3(356 / 514)$ & $88.8(138049 / 155424)$ & $2.0(356 / 17731)$ \\
Miki [17] & 80405 & 2 & $66.5(131 / 197)$ & $89.9(72194 / 80208)$ & $1.6(131 / 8145)$ \\
& & 1 & $87.3(131 / 150)$ & $90.0(72241 / 80255)$ & $1.6(131 / 8145)$ \\
Sato [18] & 92642 & 2 & $66.1(197 / 298)$ & $79.7(73569 / 92344)$ & $1.0(197 / 18972)$ \\
Fujita [19] & 34331 & 2 & $70.8(75 / 106)$ & $81.3(27806 / 34205)$ & $1.2(75 / 6474)$ \\
Murakami [20] & $85105^{\mathrm{c}}$ & 1 & $88.5(100 / 113)$ & $92.0(78189 / 84992)$ & $1.4(100 / 6903)$ \\
& $114675^{\mathrm{d}}$ & 1 & $89.6(207 / 231)$ & $85.8(98193 / 114444)$ & $1.3(207 / 16458)$ \\
Ishida [21] & $72887^{\mathrm{e}}$ & 1 & $90.8(148 / 163)$ & $91.4(66492 / 72724)$ & $2.3(148 / 6380)$ \\
\hline
\end{tabular}

a 1982

b1987

cPhotofluorography with image intensifier

${ }^{\mathrm{d}}$ Photofluorography with mirror camera

${ }^{\mathrm{e}}$ Direct radiography

${ }_{\mathrm{f}}^{\mathrm{f}}$, Gastric cancer cases identified within 1 year of follow-up; 2, gastric cancer cases identified within 1 year of follow-up, plus cases detected by the screening conducted in the subsequent year 
Table 2. Proportion of early gastric cancer and survival rates in screen-detected and symptom-diagnosed cases

\begin{tabular}{|c|c|c|c|c|c|c|c|c|}
\hline \multirow[b]{2}{*}{ Author } & \multicolumn{2}{|c|}{ No. of cases } & \multicolumn{2}{|c|}{ Early cancer $(\%)$} & \multicolumn{2}{|c|}{ 5-year survival rate } & \multicolumn{2}{|c|}{ 10-year survival rate } \\
\hline & Screened & Symptom-diag & Screened & Symptom-diag & Screened & Symptom-diag & Screened & Symptom-diag \\
\hline Ueda [22] & 68 & 397 & 58.8 & 38.3 & 74.0 & 61.0 & - & - \\
\hline Abe [23] & 274 & 1859 & 50.4 & 23.8 & 80.0 & 56.9 & 78.5 & 55.1 \\
\hline Nanba [24] & 49 & 386 & 42.9 & 27.5 & - & - & - & - \\
\hline Ohizumi [25] & 127 & 602 & 52.0 & 23.4 & 76.4 & 42.9 & 72.7 & 38.3 \\
\hline Tanabe $[26]$ & 91 & 292 & 45.1 & 30.8 & - & - & - & - \\
\hline Kobori [27] & 171 & 1087 & 53.2 & 20.5 & - & - & - & - \\
\hline Kato [28] & 77 & 55 & 53.2 & 29.1 & - & - & - & - \\
\hline Kawaguchi [29] & 103 & 320 & 57.3 & 34.1 & - & - & - & - \\
\hline Kaibara [30] & 184 & 989 & 43.5 & 24.5 & 71.3 & 54.6 & - & - \\
\hline Yamazaki [32] & - & - & - & - & 69.0 & 51.3 & 68.8 & 48.1 \\
\hline
\end{tabular}

diag, Diagnosed

Table 3. Summary of cohort studies of gastric cancer screening by photofluorography

\begin{tabular}{|c|c|c|c|c|c|c|c|c|}
\hline \multirow{4}{*}{$\begin{array}{c}\text { Author } \\
\text { Oshima } \\
{[34]}\end{array}$} & \multirow{3}{*}{$\begin{array}{c}\text { Follow-up } \\
6 \text { Years }\end{array}$} & \multirow{3}{*}{$\begin{array}{r}\text { Age } \\
\text { All age }\end{array}$} & \multirow{2}{*}{\multicolumn{2}{|c|}{ No. of subjects }} & \multicolumn{2}{|c|}{ No. of gastric cancers } & \multirow{2}{*}{\multicolumn{2}{|c|}{ Results }} \\
\hline & & & & & \multirow[t]{2}{*}{ Incidence } & \multirow[t]{3}{*}{ Death } & & \\
\hline & & & & & & & \multicolumn{2}{|c|}{$\mathrm{O} / \mathrm{E}$ ratio } \\
\hline & & & & & & & Incidence & Mortality rate \\
\hline & & & All age & 32789 & 335 & 179 & 1.37 & 0.91 \\
\hline & & & $\leq 39$ Years & 9927 & 20 & 6 & 1.46 & 0.63 \\
\hline & & & 40-59 Years & 18785 & 182 & 78 & 1.35 & 0.74 \\
\hline & & & $60-69$ Years & 3330 & 105 & 71 & 1.44 & 1.13 \\
\hline & & & $\geq 70$ Years & 747 & 28 & 24 & 1.27 & 1.19 \\
\hline \multirow{6}{*}{$\begin{array}{c}\text { Hisamichi } \\
{[35]}\end{array}$} & 18 Years & 40-69 Years & Men & & & & Incidence & Mortality rate \\
\hline & & & Screened & 2098 & 74 & 25 & 187.7 & 61.9 \\
\hline & & & Unscreened & 1287 & 44 & $\begin{array}{r}30 \\
\text { NS }\end{array}$ & $\begin{array}{c}201.8 \\
P<0.005\end{array}$ & 137.2 \\
\hline & & & Women & & & & & \\
\hline & & & Screened & 2227 & 29 & 14 & 58.1 & 28.1 \\
\hline & & & Unscreened & 1396 & 18 & 12 & $\begin{array}{l}79.1 \\
\text { NS }\end{array}$ & $\begin{array}{c}53.8 \\
P<0.01\end{array}$ \\
\hline \multirow[t]{5}{*}{ Inaba [36] } & 40 Months & 41 Years & Men & & & & \multicolumn{2}{|c|}{$\operatorname{RR}(95 \% \mathrm{CI})$} \\
\hline & & & Screened & 4934 & - & 8 & \multicolumn{2}{|c|}{$0.72(0.31-1.66)$} \\
\hline & & & $\begin{array}{l}\text { Unscreened } \\
\text { Women }\end{array}$ & 6536 & - & 19 & \multicolumn{2}{|c|}{$P=0.44$} \\
\hline & & & Screened & 4208 & - & 4 & \multicolumn{2}{|c|}{$1.46(0.43-4.90)$} \\
\hline & & & Unscreened & 8456 & - & 9 & \multicolumn{2}{|c|}{$P=0.55$} \\
\hline
\end{tabular}

$\mathrm{O} / \mathrm{E}$, Observed/expected; NS, not significant; CI, confidence interval; RR, relative risk

mortality from gastric cancer is reduced in the screened population.

\section{Efficacy of screening programs}

Although a randomized controlled trial is the most valid method of assessing the efficacy of cancer screening in reducing mortality, no results have been available on gastric photofluorography. Various observational studies have examined the benefit of screening [3-7]. We summarize here the results of cohort and casecontrol studies.

\section{Cohort study}

As summarized in Table 3, three cohort studies have examined the effect of the screening [34-36]. Oshima et al. [34] followed up 32789 residents in a town of Osaka Prefecture who were screened at least once during 1967-1970. During the 6-year period of follow-up, the average number of screenings per subject was 2.66 for men and 1.92 for women. A total of 335 incident cases of gastric cancer and 179 deaths due to the disease had been identified from the population-based cancer registry covering the district. As 243.8 incident cases and 197.7 deaths from gastric cancer were expected 
among a hypothetical general population with an identical age and sex distribution to the study subjects, the ratio of the observed to expected number of deaths from gastric cancer (O/E ratio) was 1.37 (335/ 243.8) for incidence and 0.91 (179/197.7) for mortality. The $\mathrm{O} / \mathrm{E}$ ratios of gastric cancer mortality for subjects aged up to 39 years, 40-59 years, 60-69 years, and 70 years or more were, $0.63,0.74,1.13$, and 1.19 , respectively. $P$ values or confidence intervals for the $\mathrm{O} /$ $\mathrm{E}$ ratios were not reported. The study suggests that the mortality from gastric cancer was reduced in younger subjects (up to 59 years), but not in older subjects (60 years or more).

Hisamichi and Sugahara [35] followed-up 7008 residents, aged 40-69 years, in four towns in Miyagi Prefecture during 1960-1977. A total of 4325 subjects were screened at least once, while 2683 subjects were not screened. During 18 years of follow-up, 165 incident cases of gastric cancer and 81 deaths due to the disease had been ascertained. For men and women, the incidence rate did not differ significantly between the screened and unscreened group. In contrast, the mortality rate in the screened group was significantly decreased (by 50\%) compared with the rate in the unscreened group, both for men and women. The study suggests a reduced mortality from gastric cancer among the screened subjects aged 40-69 years.

Inaba et al. [36] followed-up 24134 residents aged over 40 years in a city in Gifu Prefecture during 19921995. Based on the self-report of screening in the previous year, 9142 subjects were classified as the screened group and 14992 as the unscreened group. During 40 months of follow-up, 40 deaths from gastric cancer were ascertained. The number of incident cases was not reported. The age-adjusted relative risk (RR) and $95 \%$ confidence interval (CI) of mortality from gastric cancer for the screened versus unscreened group was $0.67(0.29-1.53)$ for men and $1.41(0.42-4.74)$ for women. Further adjustment for factors associated with the incident risk of gastric cancer (smoking; and the intake of carotene, vitamin $\mathrm{C}$, and salt) did not change the results materially, with RR (95\% CI) of 0.72 (0.31$1.66)$ for men and $1.46(0.43-4.90)$ for women. The authors concluded that the study did not demonstrate a large contribution of the screening to decreasing gastric cancer mortality. However, the small number of gastric cancer deaths (8 men and 4 women in the screened group) and the associated wide $95 \%$ CI for the RRs substantially limit the statistical power of the study to draw meaningful inference on the efficacy of the program.

\section{Case-control study}

Three population-based case-control studies have examined the effect of gastric cancer screening [37-39]. Oshima et al. [37] compared the screening histories of 91 patients (cases) who had died of gastric cancer and 261 controls in one town in Osaka Prefecture. Fukao et al. [38] selected 198 cases and 577 controls in 57 municipalities in Miyagi Prefecture. Abe et al. [39] selected 820 cases and 2413 controls in 11 municpalities in Chiba Prefecture. Controls in the three studies were matched for age, sex, and residential area to the corresponding cases.

Table 4 presents the sex-specific odds ratio (OR) of mortality from gastric cancer for subjects who had ever been screened during the study period, as compared with those who had never been screened. The studies generally showed a decreased risk among the screened subjects, both for men and women. The OR for men in the report of Oshima et al. [37] and that for women in the study of Fukao et al. [38] fail to attain statistical

Table 4. Summary of case-control studies of screening for gastric cancer by photofluorography: sex-specific odds ratios (ORs) and 95\% confidence intervals (CIs) of mortality from gastric cancer by ever vs never screened

\begin{tabular}{|c|c|c|c|c|c|}
\hline \multirow[b]{2}{*}{ Author } & \multicolumn{2}{|c|}{ No. of subjects } & \multicolumn{2}{|c|}{ Screened (\%) } & \multirow[b]{2}{*}{ OR (95\% CI) } \\
\hline & Cases & Controls & Cases & Controls & \\
\hline \multicolumn{6}{|l|}{ Men } \\
\hline Oshima [37] & 53 & 156 & 62.3 & 73.1 & $0.60(0.34-1.05)^{\mathrm{a}}$ \\
\hline Fukao [38] & 126 & 364 & 16.7 & 38.5 & $0.32(0.19-0.53)$ \\
\hline Abe [39] & 527 & 1552 & 11.2 & 23.3 & $0.37(0.24-0.57)$ \\
\hline Pooled OR & & & & & $0.39(0.29-0.52)$ \\
\hline \multicolumn{6}{|l|}{ Women } \\
\hline Oshima [37] & 37 & 105 & 40.5 & 59.0 & $0.38(0.19-0.79)^{\mathrm{a}}$ \\
\hline Fukao [38] & 72 & 213 & 26.4 & 36.2 & $0.63(0.34-1.16)$ \\
\hline Abe [39] & 293 & 861 & 11.3 & 20.6 & $0.46(0.26-0.80)$ \\
\hline Pooled OR & & & & & $0.50(0.34-0.72)$ \\
\hline
\end{tabular}

a $90 \%$ CI 
Table 5. Summary of case-control studies of screening for gastric cancer by photofluorography: sex- and age-specific odds ratios (ORs) and 95\% confidence intervals (CIs) of mortality from gastric cancer by ever vs never screened

\begin{tabular}{|c|c|c|c|c|}
\hline & \multicolumn{2}{|c|}{ Abe [39] } & \multicolumn{2}{|c|}{ Fukao [38] } \\
\hline & No. of cases & OR $(95 \% \mathrm{CI})$ & No. of cases & OR $(95 \% \mathrm{CI})$ \\
\hline \multicolumn{5}{|l|}{ Men } \\
\hline 30-39 & 14 & $2.00(0.06-72.6)$ & - & - \\
\hline $40-49$ & 28 & $0.11(0.01-0.83)$ & - & - \\
\hline $50-59$ & 90 & $0.25(0.08-0.76)$ & 20 & $0.46(0.12-1.80)$ \\
\hline $60-69$ & 162 & $0.27(0.11-0.69)$ & 40 & $0.34(0.15-0.77)$ \\
\hline $70-74$ & 89 & $0.43(0.20-0.90)$ & 66 & $0.25^{\mathrm{a}}(0.11-0.56)$ \\
\hline $75-79$ & 75 & $0.83(0.14-5.03)$ & & \\
\hline 80-89 & 69 & $1.00(1.00-1.00)$ & - & - \\
\hline \multicolumn{5}{|l|}{ Women } \\
\hline 30-39 & 8 & 0.00 & - & - \\
\hline $40-49$ & 16 & $0.78-$ & - & - \\
\hline $50-59$ & 41 & $0.20(0.06-0.71)$ & 12 & $1.07(0.28-4.06)$ \\
\hline $60-69$ & 66 & $0.39(0.18-0.83)$ & 23 & $0.45(0.17-1.19)$ \\
\hline $70-74$ & 49 & $0.88-$ & 37 & $0.63^{\mathrm{a}}(0.24-1.66)$ \\
\hline $75-79$ & 59 & $0.44(0.13-1.41)$ & & \\
\hline $80-89$ & 54 & $0.70(0.01-61.5)$ & - & - \\
\hline
\end{tabular}

a 70-79 Years

Table 6. Summary of case-control studies of screening for gastric cancer by photofluorography: odds ratios (ORs) and $95 \%$ confidence intervals (CIs) of mortality from gastric cancer by screening within years of case diagnosis

\begin{tabular}{|c|c|c|c|c|}
\hline Years & $\begin{array}{c}\text { Abe [39] } \\
\text { OR }(95 \% \text { CI) }\end{array}$ & $\begin{array}{c}\text { Fukao [38] } \\
\text { OR }(95 \% \mathrm{CI})\end{array}$ & $\begin{array}{l}\text { Oshima, men [37] } \\
\text { OR }(90 \% \text { CI })\end{array}$ & $\begin{array}{c}\text { Oshima, women [37] } \\
\text { OR }(90 \% \text { CI })\end{array}$ \\
\hline 1 & $0.38(0.25-0.58)$ & $0.45(0.28-0.70)$ & $0.29(0.10-0.84)$ & $0.08(0.02-0.32)$ \\
\hline 2 & $0.43(0.20-0.96)$ & $0.45(0.19-1.08)$ & $0.69(0.32-1.48)$ & $0.62(0.24-1.61)$ \\
\hline 3 & $0.33(0.13-0.86)$ & $0.22(0.01-0.95)$ & $\downarrow$ & $\downarrow$ \\
\hline 4 & $0.47(0.22-1.01)$ & $0.34(0.08-1.50)$ & $0.65(0.35-1.20)$ & $0.65(0.29-1.45)$ \\
\hline 5 & $0.51(0.14-1.89)$ & $0.30(0.04-2.52)$ & $\downarrow$ & $\downarrow$ \\
\hline$>5$ & $0.77(0.41-1.45)$ & 1.00 (Referent) & $\downarrow$ & $\downarrow$ \\
\hline Never screened & 1.00 (Referent) & & 1.00 (Referent) & 1.00 (Referent) \\
\hline
\end{tabular}

significance, partly due to the small number of cases. We calculated the weighted average of the ORs, using inverted variance of each OR as the weight. This pooled OR $(95 \% \mathrm{CI})$ was $0.39(0.29-0.52)$ for men and 0.50 (0.34-0.72) for women, suggesting that the screening can reduce about $60 \%$ of deaths from gastric cancer in men and $50 \%$ in women, and that there is no marked sex difference in the efficacy.

Table 5 shows sex- and age-specific OR reported by two of the above studies [38,39]. Fukao et al. [38] found a tendency of decreased ORs (increased efficacy) with advancing age, while Abe et al. [39] observed the opposite trend in men and no such tendency in women. Table 6 presents the ORs in the three studies by screening histories within specified years of case diagnosis. A significantly decreased OR was noted for up to 1 year [37], 2 years [39], and 3 years [38], suggesting that the efficacy of screening continues for up to 2-3 years prior to the case diagnosis.
A case-control study was also conducted in the state of Tachira in the western part of Venezuela, where photofluorographic screening has been conducted since 1980, using two mobile units [40]. The cases were 241 individuals who died of gastric cancer during 1985-1989. Ten live controls per case were drawn from the electoral rolls, matched for sex, age, and residence. When exposure to the screening was defined as the test conducted 1 month before the date of diagnosis of the case, the prevalence of screening was $19.9 \%$ (48/241) among cases and $11.0 \%(265 / 2410)$ among controls, and the estimated OR (95\% CI) was 2.08 (1.96-2.96). This result suggests that those who attended the screening program were at a higher risk of dying from gastric cancer than the general population, and that many attended for screening because of the presence of symptoms. When the analysis was limited to those subjects who had had at least one screening test, to avoid this selection bias, the rate of screening was 
$56.5 \%(48 / 85)$ among cases and 70.4\% (264/375) among controls, with an estimated OR (95\% CI) of 0.47 (0.24-0.98), which suggested the benefit of screening.

\section{Serum pepsinogen measurements as a screening test}

Chronic atrophic gastritis has been considered as a precursor of gastric cancer, especially of the differentiated type [41]. Serum pepsinogen I and pepsinogen II levels are predictive of the histologic status of the gastric mucosa and are well correlated with the severity of chronic atrophic gastritis [42]. Therefore, the measurement of serum pepsinogens has recently drawn attention as a candidate for a new screening test for gastric cancer. The method is particularly attractive, given its lower cost and simplicity relative to photofluorography.

Studies of serum pepsinogens have so far focused on establishing an optimal cut-off point and quantifying the sensitivity and specificity. Table 7 summarizes studies examining the accuracy of serum pepsinogen measurement in a general population setting [43-45]. Table 8 presents the results of two studies comparing the accuracy of photofluorography and serum pepsinogens in a single population $[46,47]$. The investigators in the two studies $[46,47]$ suggest that the accuracy of serum pepsinogens is comparable to, or even better than, that of photofluorography.

One methodological issue in these investigations deserves comment. When the accuracy of a cancer screening test is examined, it is desirable to report the results of initial and subsequent screenings separately. This holds particularly for a newly applied test such as serum pepsinogen measurement. The test performed for the first time in a population would detect prevalent cases at relatively advanced stages, while the test conducted subsequently in the same population would detect incident cases at less advanced stages occurring during the screening intervals (and cases missed in the previous tests) [11, pp 21-42]. Therefore, a test that is highly sensitive for the initial prevalent screening may be less so for the subsequent incident screenings. Kitahara et al. [45] report the accuracy of serum pepsinogens separately in "cross-sectional" and "prospective" evaluations, in which the former basically represents prevalent screening and the latter, incident screening. The observed sensitivity was high in the "cross-sectional" examination ( $84.6 \%$ or $10 / 13)$, but was substantially reduced in the "prospective" evaluation $(40.0 \%$ or $4 / 10)$.

In this regard, the sensitivities of serum pepsinogens and photofluorography reported by the two studies cited in Table $8[46,47]$ may not be directly comparable. The two investigations were conducted in a setting in

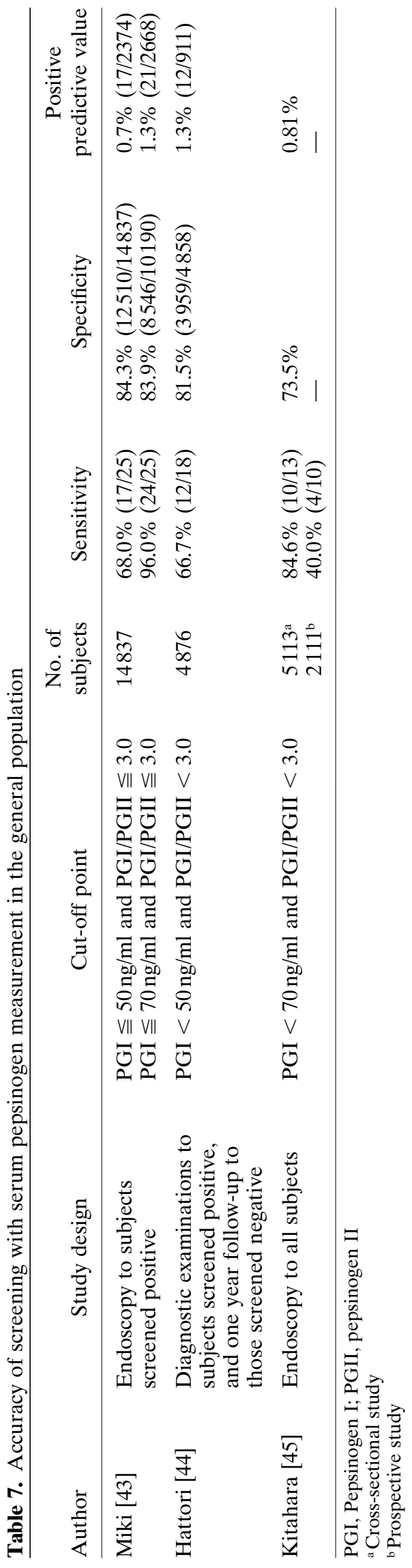


which annual photofluorographic screening had been performed; thus, the photofluorography of interest would have been a non-initial incident screening for the majority of the subjects. In contrast, the measurement of serum pepsinogens may have been performed for the first time for the majority of participants, as the test was a relatively new procedure, and hence, may have been an initial prevalent screening.

It may seem counterintuitive to regard one of the two tests performed concurrently to the same target organ site as "incident" screening and the other as "prevalent" screening. However, only a small proportion of people screened positive by serum pepsinogens were also given positive results by photofluorography $(24 \%$ according to Yoshihara et al. [47]). Therefore, the two tests gave positive results to largely distinctive subgroups in a population, and detected gastric cancers in different subgroups. Consequently, the sensitivity of serum pepsinogens may be decreased if the test is repeated in the same population, as suggested by the finding of Kitahara et al. [45]. In contrast, the sensitivity of photofluorography would not change substantially even when the test is repeated, as they had already been conducted repeatedly in the study populations. Thus, the two studies may have overestimated the relative accuracy of serum pepsinogen testing. Comparison of the two tests would be more informative if both were performed at the same phase of screening (initial prevalent screening or subsequent incident screening).

The assessment of test accuracy is only a preliminary process for the evaluation of a cancer screening program, and the examination of mortality reduction is most important. No studies have directly examined whether the screening with serum pepsinogens reduced the mortality from gastric cancer.

\section{Discussion}

Summarizing the evidence on gastric photofluorography, it is accurate and leads to early detection and better prognosis of cancer cases. Although no randomized controlled trials have been reported and a small cohort study failed to find a benefit of screening, larger cohort studies and case-control studies showed a reduced mortality from gastric cancer in the screened population. Therefore, there is substantial evidence indicating that the Japanese screening program with photofluorography is effective in reducing the mortality from gastric cancer.

As a limitation of most cohort and case-control studies [34,35,37-39], they did not address the potential for self-selection bias that may over- or underestimate the true benefit of screening. Self-selection bias could occur when characteristics associated with incident or 
mortality risk of gastric cancer differ between screened and unscreened persons in cohort studies or cases and controls in case-control studies. Statistical adjustment may be possible, to some extent, if the information on the associated variables is available, but there is no guarantee that the adjustment is complete. All observational studies that do not randomize the subjects into screening and control groups are susceptible to this distortion. Although it is not likely that the reduction in gastric cancer mortality found in the observational studies is totally attributable to self-selection bias, further studies are required to better address this problem. We are currently undertaking a case-control study nested within a population-based prospective cohort study conducted in Miyagi [48], in which information for factors associated with incidence and mortality of gastric cancer are available and the differences in these factors between cases and controls can be controlled for.

Studies also examined the economic efficiency and the safety of the screening. The cost-effectiveness of the program was shown to be better than that of screening for colorectal cancer by fecal occult blood testing [49]. No increased risk of developing leukemia following radiation exposure by photofluorography was observed [50,51].

At the same time, the program has been criticized for relatively low specificity [52], high cost [53,54], and the technical expertise required [52,53]. Therefore, the photofluorographic screening of an asymptomatic population would not be likely to be adopted widely in other parts of the world. The International Union Against Cancer (UICC) currently takes the position that, although the screening should continue in those regions with high gastric cancer incidence where they are already underway (i.e., Japan and a few countries in Latin America), it cannot be recommended in other countries as a public health policy [55].

Several investigations suggest that the measurement of serum pepsinogens has an accuracy comparable to that of photofluorography. Nevertheless, these studies may have compared the accuracy of the two tests in different phases of screening and may have overestimated the relative accuracy of serum pepsinogen testing. Furthermore, no studies have directly examined whether the screening with serum pepsinogens reduced the mortality from gastric cancer. Therefore, there is insufficient evidence at present to determine the effectiveness of the program. Evidence in terms of mortality reduction is required before any conclusions can be drawn. These investigations may not be feasible in Japan, where photofluographic screening is already widespread, because a substantial proportion of people assigned to a control group would be screened with photofluorography and the incremental effects of pepsinogen testing may not be detected. The possibility of intervention studies in high-risk countries outside Japan would be worth pursuing. Several strategies, including concurrent and serial combinations of serum pepsinogen measurement and photofluorography, have been proposed [56]. Serum pepsinogens may be used as a screening test for highrisk subjects with atrophic gastritis, rather than as a test for cancer itself, and systematic endoscopic surveillance of this group may be useful. These strategies would require empirical assessment, using mortality as an endpoint.

Despite the world decline in incidence and mortality [57], gastric cancer still remains one of the most common causes of cancer morbidity and mortality in the world today $[58,59]$, and will probably remain as such in the foreseeable future. The international collaboration of health professionals should be promoted to further advance the prevention and control of this global epidemic.

\section{References}

1. Kurihara M, Aoki K, Hisamichi S, editors. Cancer mortality statistics in the world 1950-1985. Nagoya: The University of Nagoya Press; 1989.

2. Ministry of Health and Welfare of Japan. Vital statistics of Japan 1995. Tokyo: Ministry of Health and Welfare; 1997.

3. Hisamichi S, Fukao A, Sugahara N, Nishikouri M, Komatsu S, Tsuji I, et al. Evaluation of mass screening programme for stomach cancer in Japan. In: Miller AB, Chamberlain J, Day NE, Hakama M, Prorok PC, editors. Cancer screening. Cambridge: Cambridge University Press; 1991. p. 357-70.

4. Hisamichi S. Screening for gastric cancer. World J Surg 1989; 13:31-7.

5. Hisamichi S, Sugahara N, Fukao A. Effectiveness of gastric mass screening in Japan. Cancer Detect Prev 1988;11:323-9.

6. Oshima A. Screening for stomach cancer. The Japanese program. In: Chamberlain J, Miller AB, editors. Screening for gastroenterointestinal cancer. Toronto: Hans Huber; 1988. p. 65-70.

7. Hisamichi S, Tsubono Y, Fukao A. Screening for gastric cancer: a critical appraisal of the Japanese experience. GI Cancer 1995;1:87-93.

8. Committee of National Statistics. The 1996 annual report of mass screening for digestive organs. J Gastroenterol Mass Survey 1999;37:212-30.

9. Committee of Photofluorography. Standardized method of gastric photofluorography (in Japanese). J Gastroenterol Mass Survey 1984;62:3-6.

10. Cole P, Morrison AS. Basic issues in population screening for cancer. J Natl Cancer Inst 1980;64:1263-72.

11. Morrison AS. Screening in chronic disease. 2nd ed. New York: Oxford University Press; 1992.

12. Hisamichi S, Sugahara N, Fuchigami A, Aikawa K, Nakama Y, Takeuchi Y, et al. Estimation of false negative rates in gastric cancer screening (in Japanese). Jpn J Cancer Clin 1978;24:189-94.

13. Sugahara N, Shibuki S, Hirasawa Y, Morimoto T. Characteristics of false negative cases in gastric cancer mass survey (in Japanese). Stomach and Intestine 1991;26:1357-62.

14. Iwai S, Hisamichi S, Asaki S, Kitamura H, Masuda Y, Hasama K, et al. Accuracy of gastric cancer mass survey viewed from screen 
negatives by photofluorography (in Japanese). J Gastroenterol Mass Survey 1981;50:18-22.

15. Hosokawa O. Transition in the diagnostic methods for gastric cancer and screening for gastric cancer (in Japanese). J Gastroenterol Mass Survey 1995;33:195-9.

16. Fukao A, Hisamichi S, Takano A, Sugahara N. Accuracies of mass screening for gastric cancer - test sensitivity and program sensitivity (in Japanese). J Gastroenterol Mass Survey 1992;97: 59-63.

17. Miki N, Oshima A, Tsukuma H, Hiyama T. Examination of the accuracy of screening for gastric cancer by a record linkage to the Osaka Cancer Registry. In: Fujimoto I, editor. A 1993 report of the studies on the development of effective implementations of screening programs under the Health and Medical Law for the Aged (in Japanese). Tokyo: Japanese Public Health Association; 1994. p. 15-24.

18. Sato Y, Matsuda T. Evaluation of the accuracy of screening for gastric cancer with cancer registry. In: Fujimoto I, editor. A 1993 report of the studies on the development of effective implementations of screening programs under the Health and Medical Law for the Aged (in Japanese). Tokyo: Japanese Public Health Association; 1994. p. 25-30.

19. Fujita M, Hattori M, Yamzaki M. Examination of the quality control in screening for gastric cancer using population-based cancer registry. In: Fujimoto I, editor. A 1993 report of the studies on the development of effective implementations of screening programs under the Health and Medical Law for the Aged (in Japanese). Tokyo: Japanese Public Health Association; 1994. p. 31-36.

20. Murakami R, Tsukuma H, Ubukata T, Nakanishi K, Fujimoto I, Kawashima T, et al. Estimation of validity of mass screening program for gastric cancer in Osaka, Japan. Cancer 1990;65:125560.

21. Ishida T, Suematsu T, Oobayashi K, Takada Y, Kimura S, Suematsu C. Measurement of accuracy of stomach mass screening by population-based cancer registration (in Japanese). J Gastroenterol Mass Survey 1994;32:9-16.

22. Ueda $H$, Mai $M$, Asai $T$, Ohta $T$, Kan $T$, Ogino $T$, et al. Clinicopathological study of screen-detected gastric cancer: a comparison with symptom diagnosed cases (in Japanese). J Gastroenterol Mass Survey 1985;69:57-65.

23. Abe Y, Fuchigami A, Fujii A, Masuda Y, Shozushima M, Yamato $\mathrm{H}$, et al. Relative survival rate of screen-detected gastric cancer: a comparison with symptom diagnosed cases (in Japanese). J Gastroenterol Mass Survey 1985;69:57-65.

24. Nanba M, Okazaki M, Azuma M, Muto K, Yokota K, Ikeguchi S, et al. A study of screen-detected gastric cancer (in Japanese). J Gastroenterol Mass Survey 1985;67:41-4.

25. Ohizumi H. Prognosis of screen-detected gastric cancer: a comparison of 10-year cumulative survival rate with symptom diagnosed cases (in Japanese). J Gastroenterol Mass Survey 1984;64:68-78.

26. Tanabe I, Kawamura S, Shinoyama T, Miyazaki S, Tanabe M, Takenami T, et al. Screen-detected gastric cancer with submucosal invasion: a comparison with symptom diagnosed cases (in Japanese). J Gastroenterol Mass Survey 1984;64:63-7.

27. Kobori O, Shimizu H, Shimizu T, Furuta Y, Maeda M, Shoji M, et al. Characteristics of screen-detected gastric cancer: a comparison with symptom diagnosed cases (in Japanese). J Gastroenterol Mass Survey 1982;56:11-5.

28. Kato H, Nishikawa H, Kusugami K, Kuwabara T, Hasegawa Y, Yoshida $\mathrm{H}$, et al. Clinicopathological study of screen-detected gastric cancer: a comparison with symptom diagnosed cases (in Japanese). J Gastric Mass Survey 1982;56:16-20.

29. Kawaguchi S, Nakazawa D, Naito Y, Yoshino J, Okamura S, Ozawa H. Characteristics of gastric cancer detected by screening with direct radiography: a comparison with cases detected by photofluorography and symptom diagnosed cases (in Japanese). J Gastric Mass Survey 1982;56:27-34.
30. Kaibara N, Kawaguchi H, Nishidori H, Kimura O, Okamoto T, Koga S, et al. Significance of mass survey for gastric cancer from the standpoint of surgery. Am J Surg 1981;142:543-5.

31. Kampshöer GHM, Fujii A, Masuda Y. Gastric cancer detected by mass survey: comparison between mass survey and outpatient detection. Scand J Gastroenterol 1989;24:813-7.

32. Yamazaki H, Murakami R, Ubukata K, Oshima A, Nakanishi K, Mori K, et al. Fifteen year relative survival rate of screen-detected gastric cancer and their causes of death (in Japanese). J Gastroenterol Mass Survey 1989;69:66-73.

33. Yamazaki H, Oshima A, Murakami R, Endoh S, Ubukata T. A long-term follow-up study of patients with gastric cancer detected by mass screening. Cancer 1989;63:613-7.

34. Oshima A, Hanai A, Fujimoto I. Evaluation of a mass screening program for stomach cancer. Natl Cancer Inst Monograph 1979;53:181-6.

35. Hisamichi S, Sugahara N. Mass screening for gastric cancer by X-ray examination. Jpn J Clin Oncol 1984;11:211-33.

36. Inaba S, Hirayama $\mathrm{H}$, Nagata $\mathrm{C}$, Kurisu $\mathrm{Y}$, Takatsuka N, Kawakami N, et al. Evaluation of screening program on reduction of gastric cancer mortality in Japan: preliminary results from a cohort study. Prev Med 1999;29:102-6.

37. Oshima A, Hirata N, Ubukata T, Umeda K, Fujimoto I. Evaluation of mass screening program for stomach cancer with a case-control study design. Int J Cancer 1986;38:829-33.

38. Fukao A, Tsubono Y, Tsuji I, Hisamichi S, Sugahara N, Takano A. The evaluation of screening for gastric cancer in Miyagi Prefecture, Japan: a population-based case-control study. Int J Cancer 1995;60:45-8.

39. Abe Y, Mitsushima T, Nagatani K, Ikuma H, Nanbara Y. Epidemiological evaluation of the protective effect for dying of stomach cancer by screening programme for stomach cancer with applying a method of case-control study (in Japanese). Jpn J Gastroenterol 1995;92:836-45.

40. Pisani P, Oliver WE, Parkin DM, Alvarez N, Vivas J. Casecontrol study of gastric cancer screening in Venezuela. Br J Cancer 1994;69:1102-5.

41. Correa P. A human model of gastric carcinogenesis. Cancer Res 1988;48:3354-60.

42. Samloff IM, Varis K, Ihamaki T, Siurala M, Rotter JI. Relationships among serum pepsinogen I, serum pepsinogen II, and gastric mucosal histology - a study in relatives of patients with pernicious anemia. Gastroenterology 1982;83:204-9.

43. Miki K. Gastric cancer screening using serum tests (stomach dry dock). Study of the systems of the first screening for cancer-susceptible subjects by serum pepsinogen levels and the secondary close-examination by every-other-year panendoscopy (in Japanese). J Gastroenterol Mass Survey 1994;32:1930.

44. Hattori Y, Tashiro H, Kawamoto T, Kodama Y. Sensitivity and specificity of mass screening for gastric cancer using the measurement of serum pepsinogens. Jpn J Cancer Res 1995;86: 1210-5.

45. Kitahara F, Kobayashi K, Sato T, Kojima Y, Araki T, Fujino MA. Accuracy of screening for gastric cancer using serum pepsinogen concentrations. Gut 1999;44:693-7.

46. Nishizawa M, Shiga T, Hayashi G. Significance of serum pepsinogen measurements in screening for gastric cancer in relation to photofluorography. In: Miki K, editor. Annual report 1998 of the Research Committee of Studies on Study of Gastric Cancer Screening System Using Serum Pepsinogen Test (in Japanese). Tokyo: The First Department of Internal Medicine, Toho University School of Medicine; 1999. p. 14-6.

47. Yoshihara M, Sumi K, Haruma K, Kiyohira K, Hattori N, Tanaka $\mathrm{S}$, et al. The usefulness of gastric mass screening using serum pepsinogen levels compared with photofluorography. Hiroshima J Med Sci 1997;46:81-6.

48. Fukao A, Tsubono Y, Komatsu S, Tsuji I, Minami Y, Hisamichi S, et al. A cohort study on the relation of lifestyle, personality and 
biologic markers to cancer in Miyagi, Japan: study design, response rate and profiles of the cohort subjects. J Epidemiol 1995;5:153-7.

49. Tsuji I, Fukao A, Sugahara N, Shoji T, Kuwajima I, Hisamichi S. Cost-effectiveness analysis of screening for gastric cancer in Japan. Tohoku J Exp Med 1991;164:279-84.

50. Fukao A, Hisamichi S, Komatsu S, Sugahara N, Takano A. Risk of leukemia among participants of gastric cancer mass screening survey in Japan: a population-based, case-control study. Cancer Detect Prev 1992;16:283-6.

51. Sakka M, Hisamichi S, Takano A, Hashizume T, Sasano N, Uzuka Y. Mass survey of gastric cancer and leukemia in Miyagi Prefecture, Japan. Tohoku J Exp Med 1982;138:239-43.

52. Miller AB. Screening for cancer: state of the art and prospect for the future. World J Surg 1989;13:79-83.

53. Report of discussion of screening for stomach cancer. In: Miller $\mathrm{AB}$, editor. Screening in cancer. Geneva: International Union Against Cancer; 1978. p. 300-5.

54. Morrissey JF. Mass screening for gastric cancer. Gastrointest Endosc 1982;28:112-3.
55. Miller AB, Chamberlain J, Day NE, Hakama M, Prorok PC. Report on a workshop of the UICC project on evaluation of screening for cancer. Int J Cancer 1990;46:761-9.

56. Miki K. Studies on Study of Gastric Cancer Screening System Using Serum Pepsinogen Test. In: Miki K, editor. Annual Report 1998 of the Research Committee of Studies on Study of Gastric Cancer Screening System Using Serum Pepsinogen Test (in Japanese). Tokyo: The First Department of Internal Medicine, Toho University School of Medicine; 1999. p. 57.

57. Howson CP, Hiyama T, Wynder EL. The decline in gastric cancer: epidemiology of an unplanned triumph. Epidemiol Rev 1986;8:1-27.

58. Parkin DM, Pisani P, Ferlay J. Estimates of the worldwide incidence of 25 major cancers in 1990. Int J Cancer 1999;80:82741.

59. Pisani P, Parkin DM, Bray F, Ferlay J. Estimates of the worldwide mortality from 25 cancers in 1990. Int J Cancer 1999;83:1829. 